\title{
Editorial
}

\section{Lecciones del escándalo financiero}

Las quiebras y las operaciones fraudulentas de bancos, financieras y empresas no son extrañas en el mundo. No hace mucho, un poderoso banco inglés se vio implicado en una defraudación millonaria. Hace más tiempo, la quiebra en serie de instituciones de ahorro y préstamo sacudió a la sociedad estadounidense, pues dejó a miles de personas sin sus ahorros. En el mundo de las finanzas, las operaciones illicitas, que con alguna frecuencia derivan en la ilegalidad, son corrientes, tal como lo demuestra la actividad de una comisión especial estadounidense, establecida precisamente para vigilar dichas transacciones.

En este contexto, es muy comprensible que en El Salvador también se produzcan quiebras bancarias y financieras en un sector que, como nunca antes, se ha expandido de una manera asombrosa debido a su alto nivel de especulación. Sin embargo, hay diferencias importantes entre lo ocurrido en paises como Inglaterra y Estados Unidos, y El Salvador. Ahl, las instituciones cumplen con bastante eficiencia sus atribuciones; aquí, en cambio, tanto ellas como los funcionarios que las dirigen se desentienden de sus responsabilidades. Con todo, se pueden sacar algunas lecciones de las cuales convendria tomar nota.

\section{La vulnerabilidad de la economía salvadoreña}

Una de las lecciones más importantes es la vulnerabilidad del sistema financiero salvadorefio. Un sistema completamente invulnerable es imposible, pero el salvadoreńo parece ser más débil de lo que se podía esperar, al menos si la economia del país es tan sólida como aseguran los voceros gubernamentales. Está demostrado que el sistema actual puede ser defraudado por cualquiera que cuente con unos recursos y una habilidad medianas. Llama la atención que, incluso, los empleados de la Superintencia del Sistema Financiero, es decir, aquellos encargados de vigilar las operaciones del sector, hayan sido sorprendidos y, en consecuencia, estén en peligro de perder sus 
ahorros. Si financieras pequeñas pueden operar con tanta libertad, cabe preguntarse qué no podrán hacer las grandes. De hecho, se reconoce, aunque no de una manera abierta, que había bancos, financieras y empresas cuyas operaciones, si no eran en su conjunto contrarias a la ley, al menos eran ilícitas; pero el escándalo los habria atemorizado y se habrían apresurado a poner sus asuntos en orden.

Hasta ahora, las instituciones bancarias y financieras han operado sin ofrecer las garantías establecidas por las normas y prácticas reconocidas internacionalmente. El control ejercido por el gobierno sobre ellas no es riguroso, dejando, por lo tanto, mucho margen para la irregularidad y la ilegalidad. Si se tienen las relaciones políticas adecuadas, la supervisión puede ser evitada o neutralizada. Los usuarios de estas instituciones, por lo general, carecen de la educación adecuada para conocer sus derechos y así poder exigirlos.

La solidez de la economía nacional depende de la seguridad y confiabilidad de su sistema financiero, sobre todo, cuando éste tiene un peso específico tan grande en aquélla. Si desde una perspectiva formal, los escándalos financieros atañen a la Superintendencia del Sistema Financiero; desde la perspectiva de la realidad salvadoreña, competen a los responsables de la economía nacional, quienes debieran reflexionar con seriedad sobre lo sucedido de cara a su consolidación y muy en particular a la promoción de la inversión extranjera.

Los grandes bancos de El Salvador no pudieron ocultar su oposición a una revisión de la legislación bancaria y financiera, pero los hechos demuestran que es indispensable establecer controles más rigurosos, incluyendo la legislación penal, en la cual los delitos financieros de viejo y nuevo cuño y sus respectivas penas - las cuales debieran tender a ser más severas- debieran ser tipificados rigurosamente. La fiscalización estatal y la aplicación de una legislación más estricta es contraria a las doctrinas neoliberales en boga, pero de nuevo, los hechos demuestran que ambas cosas son indispensables, dada la tendencia casi irresistible del capital a aprovecharse de los más débiles.

La lucha por mercados más grandes, en un contexto de crecimiento económico lento, vuelve feroz la competencia. En ella se hace uso de toda clase de recursos, sin distinguir entre lo que es y no es lícito, incluyendo salarios deprimidos, reducción de puestos de trabajo, subvaloración severa de la energía y la materia prima, y explotación predatoria de los recursos naturales. Las fuerzas del mercado buscan la ganancia máxima, independientemente de la legislación o de otras consideraciones de tipo ético o religioso. Por lo tanto, estas fuerzas no pueden dejarse abandonadas a si mismas, sino que deben ser contenidas o reprimidas, según sea el caso. Es muy probable que si el Estado salvadoréno hubiese cumplido con sus deberes de supervisión, control y sanción, las estafas que hoy lamentamos se podrian haber evitado. 
La amargura que embarga a las victimas por la pérdida eventual de su dinero demuestra de forma palpable la necesidad de un Estado claro en sus principios $y$ firme en sus determinaciones para mantener a las fuerzas del mercado dentro de los límites establecidos por la ley. En este sentido, el mercado no puede reemplazar al Estado sin pagar unos costos sociales muy elevados, y si no que le pregunten a las afectadas por los escándalos, que gritan en las calles de San Salvador su despojo.

Los banqueros también se oponen a que el secreto bancario sea levantado para investigar el escándalo, incluso, una supuesta asocia-

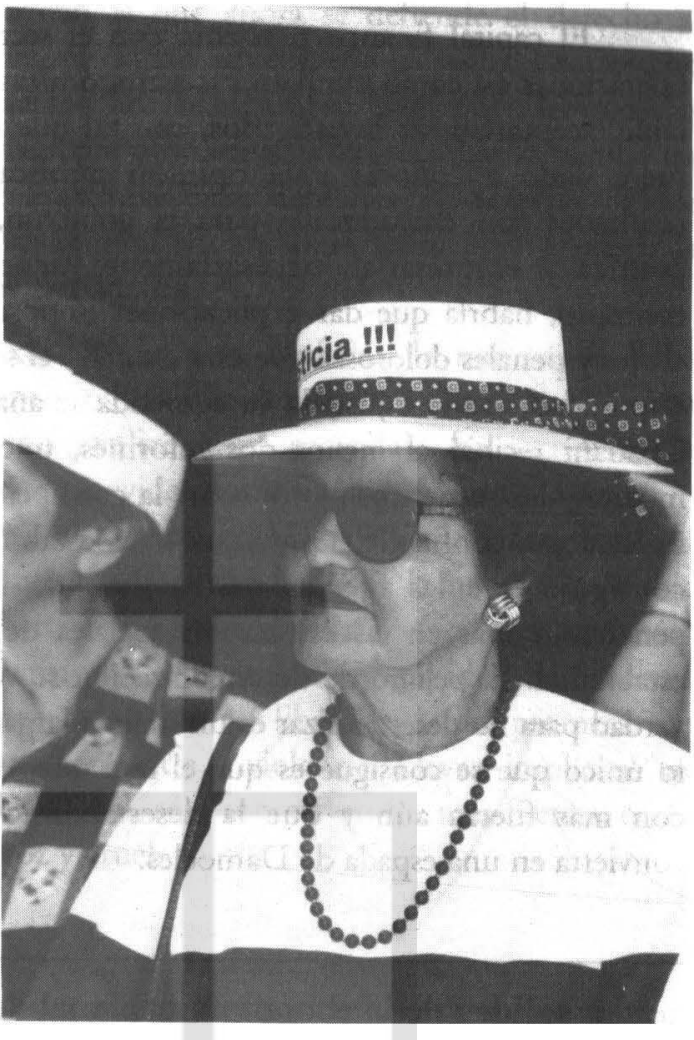
ción de usuarios - una organización fantasma al estilo de las de la década pasada-, pedía mantener intacto dicho secreto. De nuevo, si se preguntara a las víctimas, éstas se pronunciarían, de manera contundente, porque el secreto fuera levantado, por lo menos para averiguar dónde están sus millones -que es casi lo único que les interesa.

Es comprensible el temor de unos y otros a permitir que este secreto sea levantado para investigar. Una de las cosas que aparecería es el nombre de los ahorrantes y las cantidades depositadas. El problema no es tanto que éstas puedan despertar la ambición de alguno de los secuestradores de profesión que todavia quedan en el país, sino las preguntas que surgirlan sobre el origen de los fondos y las declaraciones de impuesto incompletas. Los casos típicos serian los de algunos antiguos oficiales del ejército y funcionarios públicos. Bastantes tendrían auténticas dificultades para explicar el origen de sus abultados ahorros y los vacíos en sus declaraciones fiscales. Además de las cantidades perdidas, se apreciaría en cuánto se aprovecharon de la ayuda económica estadounidense durante la guerra así como también de los fondos públicos. Al mismo tiempo, las operaciones muy probablemente ilícitas, si no es que contrarias a la ley, de bancos, financieras y empresas quedarian expuestas ante la opinión pública. 
El capital financiero cuenta con el secreto bancario para ocultar sus operaciones asl como también sus astronómicas ganancias. Pero ante lo inevitable, aceptarian ser investigados, con tal que el resultado de la pesquisa no fuera dado a conocer a la opinión pública. Las investigaciones, cuyos resultados son embarazosos para el gobierno, el partido oficial y la clase política y empresarial, necesariamente tienen que ser ocultadas. De lo contrario, habría que dar explicaciones imposibles y pedir responsabilidades civiles y penales dolorosas. De esta manera, el secreto bancario contribuye a la impunidad, y a la injusticia ya cometida se añade la injuria. El ex presidente Cristiani recibió al menos dos informes, unó sobre los escuadrones de la muerte y los secuestros y otro sobre la corrupción. Engavetó ambos y justificó su carácter confidencial invocando la estabilidad del pals. Con ello sólo consiguió que las fuerzas destructivas de la violencia y la corrupción penetraran más en las estructuras sociales de El Salvador, amenazando su estabilidad. El peligro de desestabilización se vuelve asi constante. Ocultar la verdad para no desestabilizar es un mal de larga data en El Salvador. Con ello, lo único que se consigue es que el mal que se quisiera combatir se arraigue con más fuerza aún y que la desestabilización que se quisiera evitar se convierta en una espada de Damocles.

La solidez de la economía nacional depende de la seguridad y confiabilidad de su sistema financiero

El secreto bancario protege y tutela un derecho, pero de ninguna manera puede ser invocado como un recurso para cometer $\mathbf{u}$ ocultar actividades delictivas. En el momento en que se traspasa la legalidad establecida, el secreto deja de cumplir su función primordial. La aplicación de este límite a un derecho que hasta ahora ha sido absoluto, al extremo de permitir el libertinaje, sin duda, minará la confianza de aquellos que lo utilizaban para ocultar sus actividades ilegales; pero, por otro lado, restablecerá la confianza perdida de los que han sido estafados. Además, podría servir como advertencia para aquellos que piensan dedicarse a esta clase de actividades, amparados en la impunidad con la que se puede operar en estos ámbitos. Es probable que una actitud firme por parte del gobierno salvadoreño aleje a algunos inversionistas del pás, pero se trata, casi seguro, de inversiones que no interesan, a no ser que se acepte que cualquier inversión es bienvenida, sin importar el origen o destino del dinero.

El derecho a la privacidad está garantizado por la Constitución y no sólo comprende las actividades financieras de los ciudadanos, sino también otras dimensiones de la vida social. Sin embargo, este derecho no es respetado ni 
defendido con el mismo celo con el que ahora se defiende el derecho al secreto bancario. Desde siempre, el Estado salvadoreño ha violado el derecho de los ciudadanos a la privacidad. Es bien sabido que, por ejemplo, las comunicaciones son escuchadas con propósitos políticos. Por lo tanto, los mismos argumentos que se esgrimen para defender el derecho de los ahorrantes a ocultar de la vista pública sus millones valen para proteger la privacidad integral de todos los ciudadanos.

Más allá de los reclamos de las personas estafadas, la mayoría de ellas aparentemente mujeres, al menos son las que dan la cara, cuyos ahorros han desaparecido de forma aún no explicada, el escándalo ha sacudido los cimientos de la sociedad al poner en evidencia su fragilidad. Antes la amenaza provenía de un enemigo externo al sistema; en la actualidad, el enemigo está dentro de éste. El descalabro financiero es resultado de la nueva conciencia neoliberal que sostiene una libertad prácticamente sin restricciones, que sólo obedece a la búsqueda del enriquecimiento fácil y rápido. La libertad prometida por el neoliberalismo se vuelve así libertinaje. Sus promesas de prosperidad y libertad incluyen corrupción y violencia. Llevan implícitas las semillas de su autodestrucción. Al final, sólo sobreviven los más fuertes, en lo que es un darwinismo social feroz y cruel.

\section{Crisis en las clases altas}

Aparentemente, las relaciones económicas y aun las sociales y, en particular, las operaciones financieras se fundamentaban en la honorabilidad de las partes. Es evidente que esta virtud ya pertenece al pasado. En otros tiempos, la amplitud en la aplicación de la legislación o sus vacios podían ser

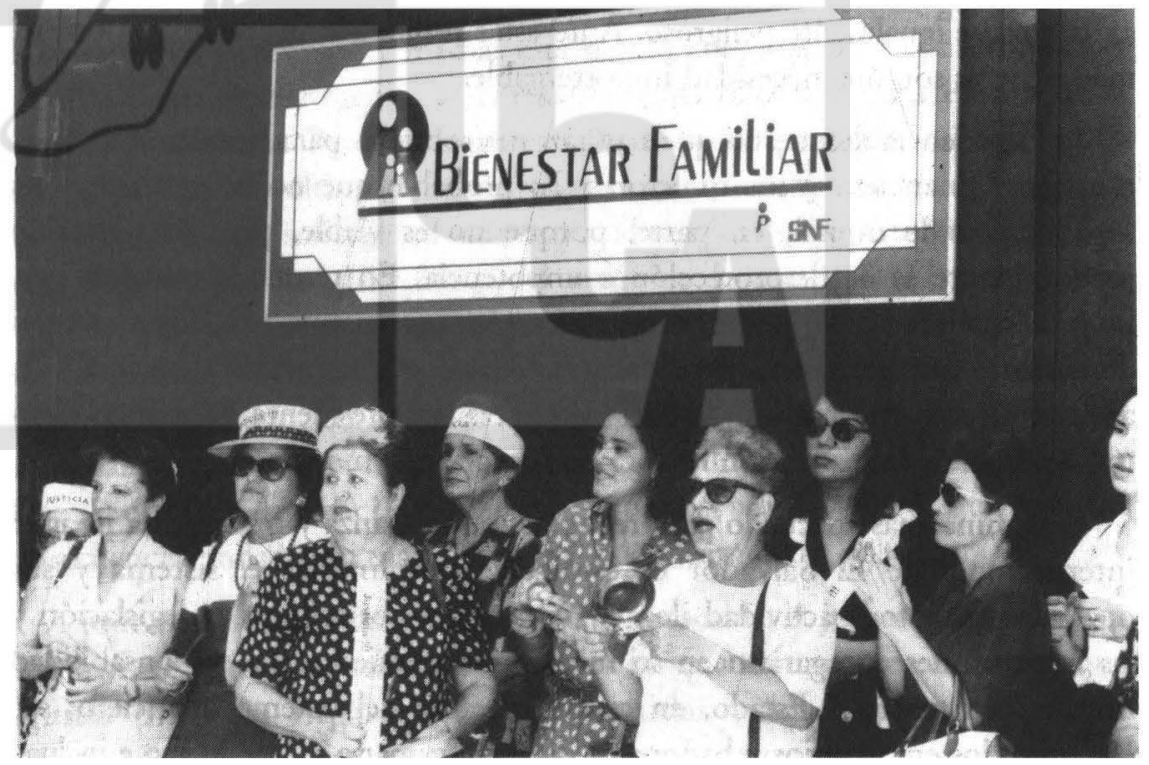


contrarrestados de alguna manera por cierto grado de honradez. Aunque eso no significa que no hubiese oportunistas y sinvergüenzas. Los escándalos financieros que conmueven a la sociedad salvadoreña en la actualidad han desvanecido la honorabilidad que podría haber habido en las familias más prestigiosas del país por su dinero y su poder. Los apellidos de estas familias están vinculados a la oligarquía cafetalera tradicional que, aunque diversificó sus inversiones, todavía mantiene mucho de la mentalidad oligárquica de principios de siglo.

Algunas estafadas explican que confiaron sus ahorros a las empresas ahora quebradas, guiadas por la honorabilidad de sus directores. Pero los hechos demuestran que los apellidos de las familias oligárquicas ya no cuentan así como tampoco su responsabilidad social e individual. Ahora cuentan las fuerzas del mercado, las cuales no reconocen apellidos, ni parientes, ni amigos, sino sólo ganadores y perdedores. Los pobres lo saben bien desde hace tiempo. El neoliberalismo los considera inútiles y descartables. En la actualidad, ya no son tanto objeto de explotación, tal como lo eran antes, sino víctimas de la alienación y la exclusión. En una palabra, engrosan las filas de los perdedores.

No obstante, algunas instituciones financieras pretenden contrarrestar el impacto que los escándalos han ocasionado en la confianza de sus clientes, invocando la honorabilidad familiar de sus directores, lo cual es inconsistente, porque en el caso de una crisis financiera, la trayectoria de aquéllas o de éstos no responderá por los ahorros. La tentación de la ganancia fácil y abundante es demasiado fuerte como para confiar sólo en las buenas intenciones de las directivas de las instituciones bancarias, financieras y empresariales. Aparte que es evidente que las consideraciones éticas tienen poco peso en las decisiones, en particular, las financieras, cuyo alto índice especulativo es asombroso e igualmente peligroso. Ante estas realidades, garantias y controles más estrictos son una necesidad impostergable.

La experiencia demuestra que hay razones sobradas para la desconfianza en el sistema financiero y sus directores. Es probable que no se produzca una fuga masiva de capital, en parte, porque no es viable, pero la sensación predominante es de desprotección e impotencia. En términos cuantitativos, las pérdidas pueden ser pequefias; pero en términos cualitativos, los directores del sistema financiero han perdido credibilidad y reconocimiento social. De ahl que se pida con tanta insistencia la cabeza del presidente del Banco Central de Reserva, la institución rectora de la economfa monetaria.

El camino más adecuado para recuperar la confianza y restaurar la imagen internacional de El Salvador es esforzarse por limpiar el sistema y sus operaciones de toda actividad ilegal y corrupta y por reforzar la legislación y las instituciones que garanticen su recto funcionamiento. La responsabilidad mayor recae sobre el Estado, en cuanto garante del sistema financiero; sin embargo, los empresarios y banqueros debieran sumarse a ese effuerzo e incluso 


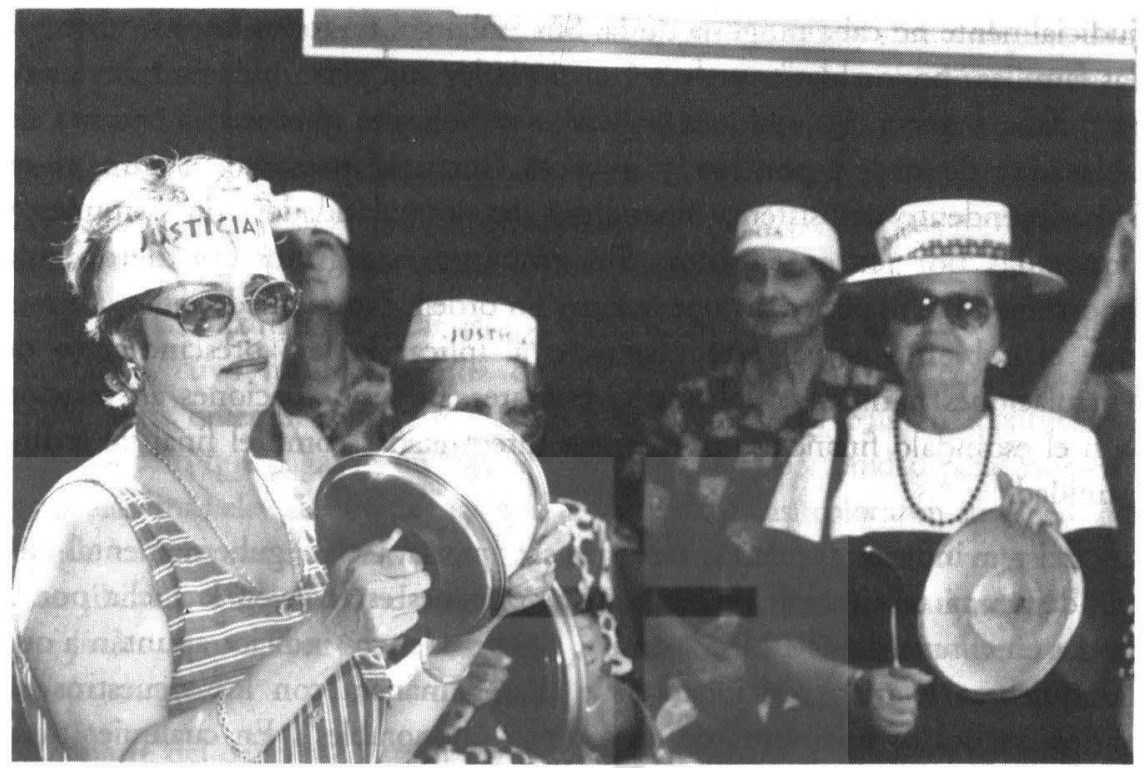

presionar para establecer un sistema financiero seguro y confiable. La propaganda sobre la honorabilidad se estrella contra la realidad de unos ahorros desaparecidos de los que no se puede dar cuenta. El daño a la confianza en el sistema financiero salvadoreño $y$, por lo tanto, a la imagen internacional del pais, lo causaron aquellos que no pueden explicar a dónde fueron a parar los ahorros de sus clientes. Es paradójico que este daño haya sido ocasionado por miembros de la misma comunidad financiera, es decir, por quienes más interesados debieran estar en resguardar la confianza y la credibilidad.

El reconocimiento social del cual los grandes capitales han gozado hasta ahora entre las clases altas y medias está siendo cuestionado. La confrontación entre las clases altas y medias y las clases populares es una caracteristica de la historia salvadorefía. Pero algunos miembros de las primeras, no satisfechos con explotar a estas últimas, osaron robar a otros de su misma clase, poniendo en entredicho una solidaridad que hasta ahora los había mantenido unidos graniticamente frente al reclamo del resto de la sociedad. El asalto a los depósitos de sus clientes es el último incidente de un proceso que comenzó con la privatización de la banca. Esta generó un resentimiento profundo, todavía no superado, en aquellos que fueron excluidos, pero que se sentían con igual derecho a participar de sus beneficios. Esta ruptura en el seno de la clase económica y socialmente poderosa es casi seguro que tendrá consecuencias todavía no manifiestas en los alineamientos políticos.

A primera vista, el gran capital ya no es intocable. A juzgar por los hechos últimos, existe un resquebrajamiento del bloque dominante, al punto que algunas prácticas ilegales serán perseguidas y los responsables serán sancionados de acuerdo con la ley. Por lo que toca a los acusados 
judicialmente no cabe ninguna duda. Sin embargo, no todos los miembros de las familias "honorables" que han violado la ley son perseguidos o tratados de la misma manera. La acciones policiales y judiciales obedecen a razones no aclaradas de orden político y a veces, incluso, personal. Según el ex superintendente del sistema financiero, las irregularidades son comunes y conocidas por los entendidos. Sin embargo, a algunos les dieron una oportunidad para poner sus operaciones en orden. No se puede, pues, afirmar que el gobierno actual esté dispuesto a aplicar la ley, prescindiendo de vinculaciones familiares, políticas o militares, ni sus actuaciones en relación con el escándalo financiero pueden ser interpretadas como el final de la impunidad.

Existen indicios fundados para pensar que la acción gubernamental responde a una motivación política, cuyos orígenes estarlan en la lucha por el poder en el seno de ARENA. Además, algunos de esos indicios apuntan a que las quiebras estarian relacionadas de alguna manera con los secuestros de varios conocidos miembros de las familias "honorables". En cualquier caso, llama mucho la atención que nadie haya querido apoyar a las empresas con problemas financieros para evitar su bancarrota así como el interés gubernamental por abrir un proceso judicial, cuyas consecuencias son impredecibles en este momento. Presentar el caso como prueba del compromiso del gobierno de Calderón con la ley y la verdad o como el fin de la impunidad de los grandes capitales salvadorefios no suavizará su impacto social y político.

\section{los directores del sistema financiero han perdido credibilidad y réconocimiento social.}

Es inevitable que el Partido ARENA sufra las consecuencias de este descalabro financiero por partida doble. En primer lugar, por haber roto con una antigua tradición de impunidad total, en un sector social que, al igual que el ejército, se consideraba más allá de la ley. Si la decisión gubernamental está motivada, en efecto, por los resentimientos y las luchas internas por el poder en el seno de ARENA, es de esperar que los perdedores reaccionen. En segundo lugar, porque muchas de las afectadas por la estafa sienten en carne propia que el gobierno de Calderón no se hace cargo de una responsabilidad que, según ellas, le corresponde. Es obvio que se sienten abandonadas por un gobierno que hasta ahora consideraban suyo. Si bien las estafadas pueden llegar a entender que ARENA y su gobiemo no puedan tolerar el delito en sus filas, no comprenden por qué retardan la devolución de su dinero. Lo más probable es que estas personas que se consideran engariadas y decepcionadas no voten por ARENA en las próximas elecciones. Es muy pronto todavía para 
apreciar el impacto que todo esto tendrá en el partido oficial. En cualquier caso, no se puede pasar por alto que ARENA está alienándose un sector importante. $\mathrm{Si}$ esto se está haciendo de manera consciente, ARENA espera obtener a cambio un beneficio mayor desconocido.

\section{El reclamo de las víctimas}

Entre las víctimas del escándalo se encuentran personas mayores de recursos limitados, cuyo futuro depende de sus ahorros, y personas con depósitos millonarios quienes, quizás, tenfan su dinero fuera del pals en instituciones seguras, pero que pagaban un interés moderado. La oportunidad para conseguir ganancias más elevadas pudo más que la seguridad y asl colocaron su dinero ahí donde los intereses eran más altos. Las víctimas que más protestan y reclaman son estas últimas, aunque no todas aparecen en público. Algunas se ocultan, sin duda, por pudor, pero tal vez porque también podrían ser cuestionadas sobre el origen de sus ahorros.

Aparte del dańo incuestionable que les han ocasionado, convirtiéndolas en víctimas de una estafa millonaria, llama la arención la agresividad de sus protestas y reclamos. Van de un lado a otro, exigiendo la devolución inmediata de su dinero. Interrumpen el tráfico en las calles de San Salvador e irrumpen en las dependencias públicas sin que nadie proteste por los inconvenientes que ocasionan. Es novedoso que miembros de la clase media y alta griten sus reclamos $y$ protestas en las calles. Hasta ahora, este recurso había sido exclusivo de las clases populares. Esta medida extrema es una muestra de su desamparo, de su desesperación y también de su profundo resentimiento, no obstante que, a diferencia de las clases populares, hay quien vele por sus intereses.

En efecto, es necesario reconocer que, en este caso, el gobierno de Calderón ha prestado atención especial a

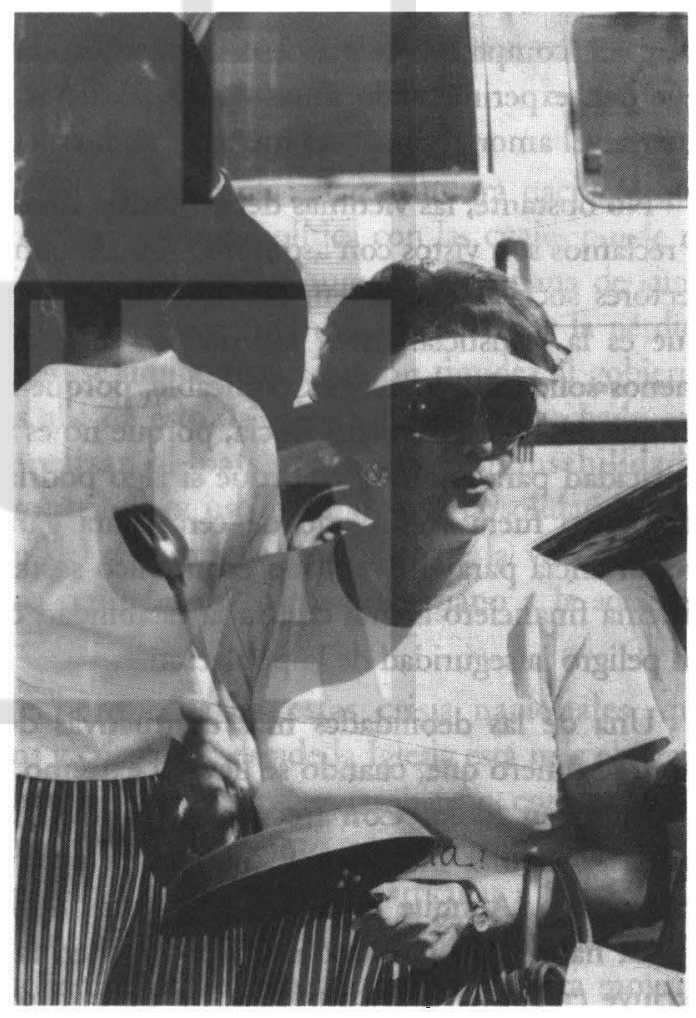


los reclamos de las víctimas de la estafa, una actitud que no tiene ante los de los sindicatos y las organizaciones populares, e intenta además hacer lo que está a su alcance para encontrar y devolver el dinero perdido. Sin embargo, las víctimas se sienten abandonadas y frustradas ante un gobierno que perciben insensible e incompetente. En realidad, están exigiendo al Estado una responsabilidad directa que éste se niega a asumir, porque de la misma manera que, fiel a su ideología neoliberal, no ejerció un control más estricto sobre las operaciones de las empresas quebradas, ahora tampoco se considera obligado a responder por el resultado que las fuerzas del mercado financiero han arrojado.

El derecho y la justicia son valores humanos universales y, por lo tanto, les son debidas a todas las personas, independientemente de su extracción de clase. Dícho esto, no se puede pasar por alto la ironía de la historia. Para quienes hoy la exigen con tanta vehemencia e incluso hasta con cólera, la justicia era algo ajeno que, en la práctica, se identificaba con la izquierda. Nunca se preocuparon por exigir justicia ante las decenas de miles de asesinatos y desapariciones forzadas ni por las otras violaciones de los derechos humanos, tampoco se imaginaron que poco después tendrían que salir a las calles a exigirla. Fueron ajenas a la justicia cuando los derechos fundamentales de los demás eran negados sistemáticamente, pero se apropian de ella al tratarse de su dinero. Han debido pasar por la experiencia del despojo material para comprender algo de la impotencia, la desesperación y el desamparo que han experimentado miles de salvadoreños, víctimas de la injusticia de la guerra. El amor al dinero es mucho más fuerte que el amor a la vida.

No obstante, las victimas del escándalo financiero están solas. Sus protestas y reclamos son vistos con asombro y quizás también con algo de ironla por los sectores sociales que saben, por una larga experiencia de pérdida y dolor, lo que es la injusticia. Estos últimos no se sienten ni interpelados ni mucho menos solidarios, lo cual es explicable, porque nunca encontraron solidaridad en quienes ahora claman justicia, porque no es su problema, ya que no tienen capacidad para ahorrar, y porque si algo podría interesarles es que el sistema financiero fuera controlado de cerca para garantizar su seguridad, dada su importancia para el desarrollo económico sostenible. En la medida en que el sistema financiero atenta contra la estabilidad de la economía nacional, pone en peligro la seguridad de la población.

Una de las debilidades más destructivas de la naturaleza humana es su amor al dinero que, cuando se lleva al extremo, lo convierte en valor absoluto e incluso en idolo. Con frecuencia, para el Estado, los ciudadanos no son iguales, son más importantes, respetados y privilegiados aquellos que tienen más dinero. Aunque tstas son constantes de la historia humana, el dinero nunca habia sido tan absolutizado como en la actualidad. La absolutización excluye cualquier otra consideración de carácter legal, ético o cristiano. Esta 
realidad responde a la dinámica de la globalización, en la cual tantas esperanzas ponen algunos. En efecto, la globalización lleva de forma simultánea a aumentar aún más la acumulación de recursos en manos de una minoría, a profundizar el deterioro de la calidad de vida de la mayoráa de la población y a la dualidad de economías y sociedades. En pocas palabras, genera ganadores y perdedores -entre los cuales se encuentran las víctimas de las estafas financieras. El poder que los ganadores llegan a concentrar es tal que pueden colocar a su servicio, a veces sin ningún pudor, a los otros poderes, incluidos el estatal y el eclesiástico.

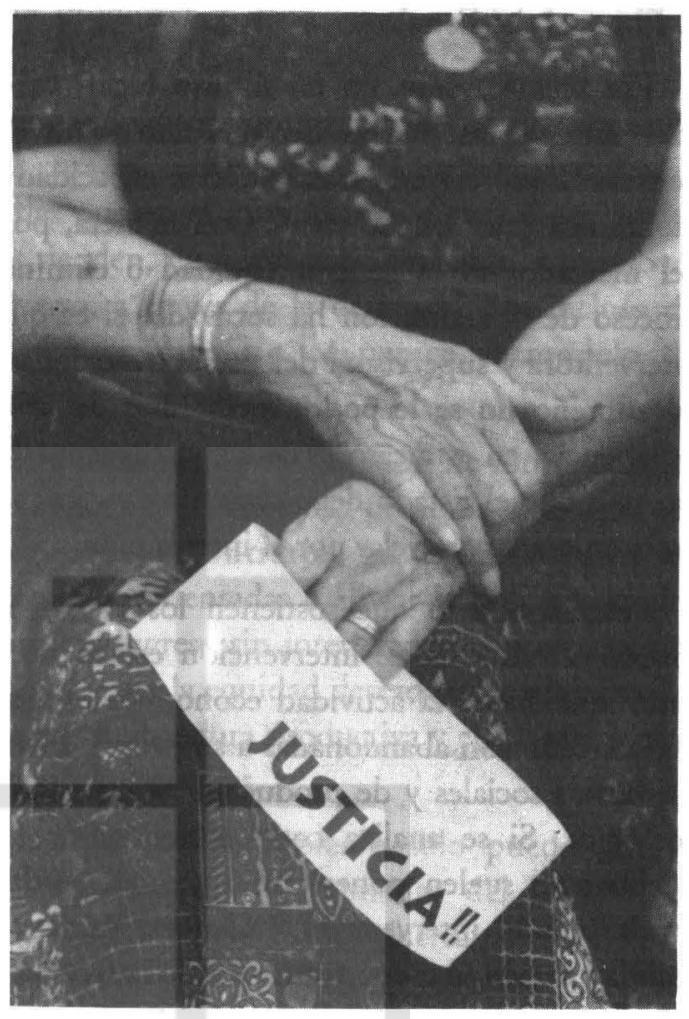

La Iglesia es una de las grandes ausentes en esta coyuntura nacional que, aunque tiene una vertiente económica y otra política con las cuales puede no considerarse afin, tiene también una dimensión humana y cristiana de suma transcendencia y de las cuales debiera hacerse cargo. Afectada por la pérdida de más de un millón de colones, se limita a solicitar con timidez al gobierno que asuma el descalabro. Más allá de esto, la Iglesia no ha aprovechado esta ocasión singular para evangelizar al país sobre las responsabilidades individuales y sociales, el recto destino y uso del dinero y la solidaridad. La lucha contra la absolutización del dinero y la prioridad de la vida sobre la propiedad debieran ser puntos centrales del mensaje cristiano a la sociedad salvadorefía.

Este vacío es lamentable porque es en estas crisis nacionales, que cuestionan los valores humanos y cristianos, donde la Iglesia está más obligada a orientar, recordando los principios cristianos, y también a consolar a las víctimas. Los escándalos financieros, en cuanto revelan mucho sobre la realidad del país, debieran recordar a todos, pero en particular a la Iglesia, el drama que vive la mayoría de la población. La negación de los valores humanos y cristianos que suponen los escándalos financieros debiera mover a insistir en su importancia para la humanización y salvación de la sociedad. 


\section{El papel del Estado}

Finalmente, pero no en último lugar, es evidente que la liberalización irrestricta de las fuerzas del mercado es incompatible con la justicia y el derecho. Estos exigen un Estado con capacidad para intervenir en la actividad económica y no puede ser de otra manera, porque el objetivo de las fuerzas del mercado no es generar equidad o eliminar la pobreza. Ahora bien, el proceso de liberalización ha socavado, si es que no destruido, esa capacidad interventora y supervisora del Estado. Desde la lógica liberalizadora, al Estado salvadoreńo no se le podrla pedir más de lo que ya hace. Sin embargo, la experiencia, en este caso la de las victimas estafadas, estarfa demostrando una vez más que el Estado debe reasumir su dimensión contralora e interventora, precisamente, para velar por el interés público.

Contrario a lo que sostienen los idéblogos neoliberales, son necesarias formas estratégicas de intervención estatal no sólo en el ámbito financiero, sino también en la actividad económica en general. Siempre que las fuerzas del mercado son abandonadas a su propia dinámica, las empresas disminuyen sus costos sociales y de producción a expensas de la equidad y la prudencia ecológica. Si se analiza con objetividad la historia de los países que los neoliberales suelen poner como modelo, todos ellos pudieron desarrollarse gracias a una intervención estatal estratégica. Más aún, los únicos que en realidad tienen una oportunidad para colocarse en la lista de los ganadores son aquellos que cuenten con un Estado fuerte.

La acción estatal estratégica necesita instituciones con capacidad para regular, gobernar y facilitar el funcionamiento del mercado. Sin ellas, la globalización no sólo no llevará al desarrollo equitativo, sino que aumentará las diferencias entre paises y sociedades. En el mejor de los casos, El Salvador como país podría encontrarse en la lista de los ganadores; pero la mayoifa de su población no saldrá beneficiada, pues la diferencia entre ricos y pobres será mayor y muy marcada. A nivel interno, sólo serán ganadores aquellos pocos que resulten favorecidos por las fuerzas del mercado; la inmensa mayoría de la población engrosará las filas de los perdedores.

el Estado debe reasumir su dimensión contralora e interventora, precisamente, para velar por el interés público.

No se puede, pues, prescindir impunemente del Estado como el neoliberalismo quisiera. A la luz de la experiencia, es necesario reflexionar sobre las ventajas insustituibles de su actuación estratégica en el quehacer nacional de cara al interés y el bien común. Aunque la globalización ha reducido bastante su autonomía, el Estado aún posee cierto grado de libertad 
que debe ser aprovechado para promover y defender el interés nacional 0 , dicho en otros términos, los objetivos del desarrollo sostenible.

A quienes todavía siguen confiando ciegamente en las fuerzas del mercado como el instrumento principal para asignar recursos y organizar la actividad económica habría que recordarles que en el mundo real, dichas fuerzas y los grupos de poder detrás de ellas tienden, de forma casi inevitable, a promover un patrón de crecimiento perverso, a través de la desigualdad o incluso de crecimiento con desarrollo. La realidad no se parece al modelo de competencia perfecta y transparencia democrática.

Si lo que se busca es el desarrollo sostenible y disminuir de forma drástica el nivel apabullante de la pobreza actual, la tendencia predominante debe ser detenida en algún momento. De lo contrario, las protestas sociales continuarán y el costo de las políticas orientadas a aliviar la pobreza seguirá siendo elevado. La redistribución del ingreso sin interferir en la producción y el consumo no es suficiente para alcanzar la equidad deseada y justa. Para ello, el Estado tendría que intervenir en la estructura productiva y en la del empleo asf como en el acceso a los activos y los recursos.

Por lo general se asume que la liberalización sólo puede arrojar resultados positivos. Se da por hecho que el aumento del ingreso, el crecimiento del empleo y la expansión del comercio se refuerzan mutuamente. De esta manera, la liberalización estimularía el crecimiento económico y la generación de empleo. Es cierto que la liberalización y la globalización no son males ni bienes absolutos, como tampoco lo son los otros modelos económicos, pero tampoco es el atajo mágico que lleva al reino de la prosperidad y la felicidad. Ambas producen ganadores y perdedores entre los países y las sociedades nacionales. Peor aún, el abismo que los separa en lugar de cerrarse, se amplía todavia más. Los ricos y los pobres están viviendo cada vez más en mundos más separados y contrapuestos. Esta tendencia no será revertida con los procesos de liberalización, integración y globalización actuales, sino que éstos deben ser controlados más de cerca, nacional e internacionalmente, así como también deben ser sometidos a reglas más estrictas.

Si los principios éticos y cristianos no son suficientes para frenar la avaricia y el libertinaje, la alternativa que queda es el fortalecimiento de las instituciones estatales encargadas de controlar las operaciones financieras e imponer penas severas a aquellos que osen burlarlas. Lo que no se puede permitir es que las cosas sigan tal como hasta ahora, arguyendo que se trata de casos aislados, cuyo significado dentro de la actividad financiera sería muy pequeño. Si los principios éticos y cristianos carecen de sentido para quienes toman las decisiones y las ejecutan, las consecuencias económicas negativas de la corrupción y la violencia debieran tener fuerza suficiente como para hacerlos entrar en razón. La solidez de la economía depende en gran medida 
de un sistema financiero seguro y confiable y de una empresa privada responsable ante si misma, sus clientes y la sociedad.

Sin duda, es positivo que se pidan cuentas y se persiga el delito. Es lamentable, sin embargo, que estos casos no puedan considerarse ejemplares, por ser selectivos y responder a intereses no aclarados. En realidad, no están motivados por el amor a la verdad, al derecho y a la justicia, sino que obedecen más a oscuras razones de lucha política. Al no haber una intención política recta, la persecución de estos delitos financieros no refuerza la institucionalidad del Estado, pues los imputados no estarlan ahora en la cárcel ni enfrentarían procesos judiciales si no hubieran caido en desgracia ante los círculos del poder. La conclusión obvia sería, entonces, que conviene estar a buenas con él.

Es cierto que la persecución de estos dos escándalos ha permitido constatar lo que ya se adivinaba sobre los manejos illícitos e ilegales de bancos, financieras y otras empresas, que en unas pocas semanas la mayoría de ellas puso en orden sus asuntos cuando habían operado ilegalmente durante ańos y que a partir de ahora el sistema financiero probablemente será más cauteloso, pero de aquí no se sigue que estén convencidos de la necesidad de revisar la legislación, de actuar apegados a ella y mucho menos de cumplir con sus responsabilidades sociales, éticas y cristianas. Si no se da un cambio de mentalidad, respaldado por una legislación más estricta y por un control más riguroso por parte del Estado, volverán a las andadas. La razón es muy sencilla, quieren triunfar en una competencia feroz e interminable, donde o se gana o se pierde.

San Salvador, 20 de agosto de 1997. 